\title{
Hume on the Laws of Dynamics: The Tacit Assumption of Mechanism
}

Abstract: I shall argue that when Hume refers to the laws of dynamics, he tacitly assumes a mechanism. Nevertheless, he remains agnostic on whether the hidden micro-constitution of bodies is machinelike. Hence this article comes to the following conclusion. Hume is not a full-blown mechanical philosopher. Still his position on dynamic laws and his concept of causation instantiate a tacitly mechanical understanding of the interactions of bodies.

\section{Introduction}

Hume's philosophy of laws of nature is well known, in particular in the context of philosophy of religion and Bayesian confirmation theory. There is a myriad of literature on his critique of the reliability of reported religious miracles, and on the application of conditional probabilities in epistemic considerations. ${ }^{1}$ His analysis of laws has been influential in subsequent accounts of the metaphysics of laws. In contemporary philosophy of physics, it is a commonplace to introduce two rival positions on laws of nature: the Humean and the nonHumean positions. The former position maintains that laws are records of universal generalizations which do not instantiate necessity. The latter maintains that laws govern and necessitate the behavior of objects. ${ }^{2}$

In the above-mentioned contexts, Hume's outlook (or the Humean outlook) on laws has been thoroughly examined. There is nevertheless one specific issue which has largely been neglected by Hume scholars and historians of philosophy of science. It is Hume's position on the laws of dynamics (henceforth LoD). ${ }^{3}$ To remedy this neglect, this article concentrates on 
this specific issue. It provides a comprehensive analysis of Hume's position on LoD and its relevant intellectual background in the history of early modern natural philosophy.

To that end, this article is structured as follows. $§ 2$ starts with a brief methodological note. This section indicates that we should not analyze Hume on LoD from the viewpoint of contemporary axiomatic exposition of the laws of Newtonian dynamics. This might lead us to evaluate Hume's views anachronistically. To analyze his position properly, it is necessary to trace his views back to their probable intellectual sources. These are notably both Cartesian and Newtonian natural philosophies. $\S 3$ shows that Hume's position on LoD is causal. According to Hume, causes and effects are contiguous, successive, and separable. This indicates that Hume's understanding of LoD is mechanistic. $\S 4$ analyzes the extent to which it is mechanistic and argues that he diverges from his mechanistic predecessors such as Boyle and Locke. There is no evidence coming from our five senses to confirm that the hidden microstructure of bodies is machinelike. In Hume's rigidly empiricist and skeptical theory of perception and causation, we are not licensed to infer what the hidden micro-constitution of bodies is, or in what relation this putative constitution is to macroscopic bodily causation. The closing section $\$ 5$ will advance the main thesis of this article: Hume is not a full-blown mechanical philosopher but his references to LoD together with his concept of causation instantiates a mechanical understanding of the interactions of bodies. This result also sheds light on the issue of why Hume's concept of causation is in tension with Newtonian dynamics. The reason is that Hume holds on to some pervasive assumptions of the push-andpull mechanical model of the universe. To agree with the results of Newton's natural philosophy, he would need to discard such a mechanistic model, and replace it with an alternative concept of causation. 


\section{Hume's references to the laws of dynamics}

Hume refers to LoD in his Treatise, in his Enquiries, and in his Dialogues. ${ }^{4}$ Before rushing into his treatment of these laws, let me issue a word of caution. It would be convenient to list Hume's references to LoD with the aid of a contemporary axiomatic exposition. Today we can portray the dynamics of the $17^{\text {th }}$ and $18^{\text {th }}$ centuries in the form of four basic laws: Newton's three laws of motion and his law of universal gravitation. In approaching Hume's position, we could look at a contemporary exposition and compare it to his listing of LoD. However, it would be insufficient, even misleading and anachronistic, to use this approach to understand Hume's position on LoD.

Establishing the foundations of classical physics as we now know it took some hundreds of years. What the early moderns had at their hands was rather different as what we have today. Nowadays, when we open a physics textbook, we find a plethora of interconnected concepts: Force, impulse, momentum, energy, heat, power and work, to mention a few. ${ }^{5}$ There is a scarce number of definitions or laws from which these concepts can be derived from. Different dynamic notions have precise meanings, and they are clearly related to each other.

It would be a momentous task to figure out how exactly our present exposition of classical physics differs from (or agrees with) early modern natural philosophy. This is not my task in this article. Here it suffices to say that the list of propositions concerning physical laws in the early modern world was not the exact same list as we have today. There were still some serious debates between the Cartesians and the Newtonians about how to organize such a list. This ambivalence is also apparent in Hume. It can be explained by his education. It included the study of Newtonian natural philosophy with the texts of Newton's disciples John Keill 
and David Gregory, as well as Cartesian natural philosophy with Jacques Rohault's textbook. In addition, Hume studied Boyle's experimental mechanical philosophy. ${ }^{6}$ His overall position on LoD — and natural philosophy more broadly conceived-reflects both Cartesian and Newtonian elements.

In my interpretation, Hume recognizes five LoD. He does not present them in an axiomatic form. This is because he is not first and foremost a natural philosopher. Hume's ambition is to develop a science of human nature that is different from natural philosophy. A central aspect of this ambition is to provide a mental geography by mapping the cognitive structures of the human mind. For this purpose, LoD are irrelevant. ${ }^{7}$ There is no evidence that Hume has anything like an account of LoD. He does not have a settled dynamical theory that he articulates throughout all his works. Instead, on various scattered occasions, he refers to a number of laws of motion in the process of making other points relevant to his overall philosophical project. These references do not explicitly tell us whether Hume approves or disapproves of the propositions in question. Often he does not even state the propositions in his own voice. He instead quotes from natural philosophers or attributes them to common viewpoints. He does not seem to have any deep concerns about their consistency. But Hume's references to LoD do tell us, or so my argument propounds, about his tacit mechanistic assumptions wedded to his notion of causality.

In various unrelated contexts (T 2.3.8.8; SBN 434-435, EHU 7.25n; SBN 73, fn. 16, 4.13; SBN 31, DNR 8.11; KS 186), Hume expresses LoD as follows:

I. "A body at rest or in motion continues for ever in its present state, till put from it by some new cause." 
II. "A body impelled takes as much motion from the impelling body as it acquires itself."

III. "The moment or force of any body in motion is in the compound ratio or proportion of its solid contents and its velocity."

IV. "The equality of action and re-action seems to be an universal law of Nature."

V. "Gravitation of matter [...] produces a motion from the one to the other."

The fact that Hume mentions law I is neither surprising nor controversial. The law is the principle of inertia. I can be found both in Descartes' and Newton's Principias. ${ }^{8}$ In Descartes' formulation, the law states: "The first law of nature: that each thing, as far as is in its power, always remains in the same state; and that consequently, when it is once moved, it always continues to move" (Pr II 37). For his part, Newton writes: "Every body perseveres in its state of being at rest or of moving uniformly straight forward, except insofar as it is compelled to change its state by forces impressed" (Principia, Axioms, or the Laws of Motion). ${ }^{9}$ Hume discusses law $\mathbf{I}$ in the context where he declines Malebrancheian theistic occasionalism. In the Malebrancheian view, God is the only causal agent in the world. Malebranche thought, to quote from Steven Nadler, that "God is directly, immediately, and solely responsible for bringing about all phenomena." 10 Whether we are dealing with bodily, mental, or mind-body causality, these are all occasions for God to cause an act of His will in as much it is in accordance with laws of nature (except for miracles). In Hume's account, we know inductively that there are certain laws of motion. But we are not justified to infer that 
God constantly recreates the world to prevent the dissipation of forces. Hume is simply unwilling to discuss the theological and metaphysical underpinnings of vis inertiae or vis viva.

Law II is a conservation law. Hume mentions this in the same footnote of his first Enquiry as law I, but he also analyses a definition used in the law. Law II applies in the special case when the masses of two bodies of an isolated system are equal. After the impact of say, two billiard balls, the velocity of the object ball will be the same as the initial speed of the cue ball. ${ }^{11}$ III is a definition which explicates the constant, the preserved quantity in law II. Hume mentions law III (to be precise, III is not a law but a definition used in law II) when discussing the notion of mixed mathematics. In introducing III, he ponders whether applied mathematics is like pure mathematics, a priori and necessary, or whether its propositions are factual like other epistemically high-class, provable propositions. ${ }^{12}$ III says that the total momentum or force (Hume conflates the two) equals the bulk of the matter and the resultant velocity of the body jointly. Hume goes on to explain the definition in this law further. He writes that

consequently [...] a small force may remove the greatest obstacle or raise the greatest weight, if, by any contrivance or machinery, we can encrease the velocity of that force, so as to make it an overmatch for its antagonist" (EHU 4.13; SBN 31).

The quotation above indicates that Hume thinks that force is proportional to the product of the weight and the speed of a body. Charles Twardy notes that Hume probably got this conception from Huygens. It might be an imitation of his work which equated forces with the powers of "raising a weight."13 
IV is Newton's third law in his Principia. Hume mentions it only in the Dialogues (8.11). It is part of Philo's argument that challenges a received view according to which a divine mind can create matter. This argument points out an inconsistency in the view that thought might influence matter. Because of Newton's third law, it was known that action on "matter" has “an equal reciprocal influence upon it" (DNR 8.11; KS 186). If non-material mind affects matter, the matter should affect the non-material mind with equal and opposite force. But we do not see this happening. The received view which maintains that an immaterial mind causes changes in the material world is hence inconsistent with the known laws of nature.

Newton himself puts his third law as follows: "To any action there is always an opposite and equal reaction; in other words, the actions of two bodies upon each other are always equal and always opposite in direction" (Principia, Axioms, or the Laws of Motion). On a superficial level, Hume agrees with Newton's formulation. But there is a crucial aspect missing in Hume's understanding. This lack of understanding is relevant in assessing the relation between Newton's third law and the concept of force. Although Philo's line of argument in the Dialogues (8.11) brings up the notion of interaction, Hume does not consistently understand the concept of force in terms of interaction. To expound on this difference, it is useful to quote from Max Jammer's study of the history of the concept of force:

The third law [...] supplies an additional important characteristic of force not mentioned previously [in Newton's first and second laws of motion]: force manifests itself invariably in a dual aspect; it is action and reaction simultaneously. Much as business 
transaction can be regarded both as a purchase and as a sale of the same amount, force can be considered as action as well as reaction of the same magnitude. ${ }^{14}$

In Newton's account, if there were just one massy particle in the universe, no forces would appear. ${ }^{15}$ Forces are not qualities hidden in bodies but dynamic relations among them. When Hume refers to the concept of force, he seems to understand it as a property of an individual object (interestingly, this also seems to have been Newton's position in his pre-Principia tract "De Gravitatione"). ${ }^{16}$ Hume notes that force is "the unknown circumstance of an object" (EHU 7.29; SBN 77, fn. 17). Force fixes and determines "the degree or quantity of its effect [the resultant motion of a body]." The concept of force is an instrument which enables one to predict the change of motion of bodies. Accordingly, Hume does not emphasize the interactive dynamic character of forces. He does not say that forces appear among massy particles, or that mass is the resisting factor in acceleration.

At first sight, $\mathbf{V}$ seems to be a rather generic description of gravitation in a two-body system. We might think that Hume is quoting from Newton's Principia, as this work is the original publication for the argument of the law of universal gravitation. In its original context, Hume is not however leaning on Newton. Hume uses $\mathbf{V}$ as an example of a body moving from a higher spatial position to a lower one due to gravitation: "There is no natural nor essential difference betwixt high and low" because "this distinction arises only from the gravitation of matter, which produces a motion from the one to the other" (T 2.3.8.8; SBN 434-5). Hume's depiction here is clearly not a reference to Newton's law of universal gravitation. But in the second Enquiry (6.6; SBN 236), Hume mentions a special case of Newton's law of universal gravitation, as he claims that the Moon is kept "in its orbit by the same force of gravity, that makes bodies fall near the surface of the earth." This makes his understanding of gravitation 
somewhat Newtonian. There are still the following restrictions: Hume does not mention the direct proportionality of masses or the inverse-square proportionality of distance in gravitational attraction.

Next, I shall proceed to analyze Hume's causal conception of laws. In what sense are dynamic laws causal? In brief, the answer is that forces cause bodies to change their state of motion; they are the causes of accelerations. In Hume's image of LoD, the way of relating force to motion is all but self-evident. An important aspect of his position is the assumption of mechanism.

\section{Causation and mechanism in laws}

Why does Hume think that laws are causal? To understand his position, it is necessary to briefly explain his "fork," that is, his distinction between the two propositions of knowledge. In the fourth section of the first Enquiry, ${ }^{17}$ Hume divides "all the objects of human reason or enquiry [...] into two kinds": relations of ideas and matters of fact. Relations of ideas include, for example, the truths of pure, non-applied mathematics, such as the theorems of algebra, arithmetic and geometry. Relations of ideas are intuitive, or demonstrable by a sequence of intuitions. Propositions concerning matters of fact are causal (T 1.3.1). ${ }^{18}$ Hume makes a universal claim that "all reasonings concerning matter of fact seem to be founded on the relation of Cause and Effect" (EHU 4.4; SBN 26). Laws of physics are generalized causal principles, as they are informative of what sorts of effects (body motions) are to be expected in what sorts of antecedent circumstances. Reasoning concerning laws is accordingly founded on the same factors that establish other causal principles: association based on past 
experience of conjunctions between types of events. In a word, LoD are causal and informative of how bodies move.

In Hume's analysis of dynamic laws, causal language is rampant. It should be noted that he does not use the concept of force in an exact way. Occasionally, he substitutes it with moment (momentum), power and energy. When addressing dynamic concepts like gravity, force, power, energy, and momentum, Hume uses active words, that is, verbs like cause, produce, impel, fix, determine and make. The causal analysis of laws is especially transparent with regard to the law and the force of gravity. The law belongs to "the most establish'd and uniform conjunctions of causes and effects" (T 1.3.8.14; SBN 104); the force is a cause "which determine[s] it [an object] to fall" (T 1.3.11.10; SBN 128); it is among "the ultimate causes and principles which we shall ever discover in nature" (EHU 4.12; SBN 30). "The production of motion by [...] gravity is an universal law," (EHU 6.4; SBN 57) as the Moon is kept "in its orbit by the same force of gravity, that makes bodies fall near the surface of the earth" (EMP 6.6.; SBN 236). The "laws and forces" of gravity govern and direct "the revolutions of planets" (EHU 1.15; SBN 14).

It is not surprising that Hume understood dynamic laws in causal terms. Both Cartesian and Newtonian natural philosophies are essentially causal in their make-up. What makes Hume's conception a distinctly mechanical one is his explicit constraints on causation. These constraints are expressed in his rules by which to judge of causes and effects (T 1.3.15). I shall focus on two of his criteria: contiguity and the separability of causes and effects. These criteria imply that Hume is, in a relevant sense, a mechanical philosopher. 
Before making any interpretation of Hume's commitment to, or assumption of mechanism, it is essential to clarify the notion of "mechanical philosophy." The term "mechanical philosophy" is not a settled term. It cannot be defined by listing a few necessary and sufficient conditions which should be included in the definition. Rather, "mechanical philosophy" is an umbrella term which has various interrelated meanings. In the formulation of Sophie Roux and Daniel Garber, ${ }^{19}$ it can be interpreted to stand for the four following commitments:

(1) "the general program of substituting for the "common philosophy," i.e. the scholastic philosophy, a new philosophy, still to be identified;"

(2) "the more specific rejection of Aristotelian hylemorphism and the correlated adoption of an ontology according to which all natural phenomena can be understood in terms of the matter and motion of the small corpuscles that make up the gross bodies of everyday experience alone;"

(3) "the comparison of natural phenomena, most specifically the world and animals, to existing or imaginary machines;"

(4) "lastly, the ontology associated with mechanics as a new mathematical science of motion, the laws of which are described as the laws of nature in general."

Hume's concept of causation instantiates mechanical philosophy in the senses of (1) and (3), as I shall argue in the subsequent subsections of this article. Hume's criterion of contiguity indicates that he formulated his causal philosophy as taking its model from the workings of 
machines. This corresponds to Roux's and Garber's point (3). His argument for the separability of causes and effects indicate his rejection of the older Aristotelian philosophy of causation in which "effects" are included in "causes," hence corresponding to point (1). Nevertheless, Hume is not a mechanical philosopher in the sense of (2), as I shall argue in the subsequent main section. His radically empiricist and skeptical theory of perception and causation does not license us to infer that bodies have a machine-like microstructure as the corpuscularian hypothesis suggests. I will not take a stand on (4).

\subsection{Contiguity}

Newtonian dynamics violates a core aspect of mechanical philosophy. Newton's third law together with the law of universal gravitation imply instantaneous action at a distance among all the massy particles in the universe. No matter how long the distance, or how small the masses, the laws countenance instant non-mediated causal action between the particles. Newton could not identify any agent which is responsible for gravitational motions. ${ }^{20}$ Newton understood space as being an empty ${ }^{21}$ Boylean vacuum, a place which bodies fill. There is nothing in space which "might impede, assist, or in any way change the motions of bodies" (Principia, General Scholium, "De Gravitatione," Definitions 2 and 4). Thus there is instantaneous action among discrete objects, although there is nothing in between them.

In his Treatise, there is one central paragraph (T 1.3.2.6; SBN 75) in which Hume discusses contiguity in physical causation. This implies his suspicion of action at a distance:

I find in the first place, that whatever objects are consider'd as causes or effects, are contiguous; and that nothing can operate in a time or place, which is ever so little 
remov'd from those of its existence. Tho' distant objects may sometimes seem productive of each other, they are commonly found upon examination to be link'd by a chain of causes, which are contiguous among themselves, and to the distant objects; and when in any particular instance we cannot discover this connexion, we still presume it to exist. We may therefore consider the relation of contiguity as essential to that of causation.

To find Hume reluctant in accepting action at a distance is not surprising. Many early modern scholars were generally hesitant to subscribe to long-range causal action. Galileo, Descartes, Huygens, Leibniz, Locke and even Newton himself thought that supposing bodies to act across empty space was troubling. ${ }^{22}$ Leibniz, in his correspondence with Clarke, famously ridiculed the notion of gravitational attraction. In his words, it is "a chimerical thing, a scholastick occult quality."23

Hume suggests that it is desirable to find an explanation which includes a reference to contiguity in LoD. If contiguity is not discovered in causal relations, it is still presumed to exist. Hume posits that in physical causation there needs to be contact among causally related bodies. In this respect, Hume lends his support to Cartesian cosmology. ${ }^{24}$ Both Hume and Descartes are very hesitant in accepting the existence of a vacuum. They are both plenists: there is no empty space independent from bodies (or at least, we have no clear and distinct idea of it). Descartes claims in his Principles (II 16) "that it is contradictory for a vacuum, or a space in which there is absolutely nothing, to exist." In the same manner, Hume claims that it is "impossible to conceive either a vacuum and extension without matter" (T 1.2.4; SBN $40) .^{25}$ 
As Hume approves this part of Cartesian cosmology, there is no action at a distance across empty space because there is no empty space in the first place (or we do not have its putative idea). ${ }^{26}$ In this mechanistic model of causation, "phenomena result," Katherine Dunlop writes, "from something like pushing or pulling, localized to the surface of the body." 27 Hume is a mechanical philosopher in this sense. Bodies' motions are generated in a way that is reminiscent of the way mechanical devices produce a chain of motion. This is apparent in the way that, for example, a water mill is used to crush grains. There is a succession of physical contacts among the parts of the machine.

In the first Enquiry, the contiguity requirement disappears. Its absence could be interpreted as Hume's shift from Cartesianism to Newtonianism. This might be in part true; the Enquiries are maybe somewhat more Newtonian than the Treatise. Another reason for Hume to drop contiguity might have been the recognition, stated explicitly already in the Treatise, that many entities that do not exist in space can enter into causal relations. The initial discussion on contiguity in Treatise 1.3.2.6 includes a reference to T 1.4.5, probably to its paragraphs 912. In paragraph 10 Hume provides a metaphysical maxim according to which "an object may exist, and yet be nowhere" ( $\mathrm{T}$ 1.4.5.10; SBN 235). He finds it very plausible that "the greatest part of beings do and must exist after this manner." There can be constant conjunctions between objects of perceptions "which exists without any particular place" (T 1.4.5.12; SBN 237), and these conjunctions still count as causal relations.

We are only left with speculation as to why Hume does not explicitly mention contiguity in his treatment of causation in the Enquiries. But I do not think that he completely gave up his initial suspicion of action at a distance. A perusal of the first Enquiry — with respect to his concept of causation, at least - suggests that he does not dismiss mechanical philosophy 
altogether. Hume's assumption of mechanical philosophy is apparent in many of the examples he provides on causality: collision of billiard balls, vibrations of strings, operations of clocks, strings, wheels and pendulums (EHU 4.9, 7.29, 8.13; SBN 29, 77, 87). These examples indicate that he is not, even in the first Enquiry, entirely jettisoning the mechanical model of causation. Moreover, Hume does not make the positive claim that there is causal action at a distance.

To say that Hume is a mechanical philosopher because of his contiguity stipulation raises the following critical question. By contiguity, does Hume mean specifically contact action? Contiguity could be interpreted as meaning a "next-to" relation. For example, I am contiguous with my neighbor. This does not mean that I am continuously standing shoulder to shoulder with my neighbor. Furthermore, the meaning of contiguity is different if Hume understands causation to concern species of events instead of objects. An event is much more unspecified than an object, such as a discrete material body. An event is not localized in space and time in the same precise way that a body is.

Even if contiguity in Hume means simply a "next-to" -relation, and even if causal relations pertain rather among events than objects, it still does not make his position compatible with dynamic causation. In Newtonian dynamics acceleration is simultaneous with the exerted force. Throughout Hume's work, succession is a necessary requirement for causation (see especially T 1.3.2.7; SBN 75-6). Causes come before the effects in time. But such philosophy of causation is incoherent with Newtonian physics. Consider the following example. I hold a rock in my hand. I release it and it falls. In Hume's assumption, this scenario should be interpreted as my releasing of the rock is an event (cause) that precedes the event of falling (effect). But in Newtonian physics, the gravitational attraction between the rock and the Earth 
is constant and instant. Gravitational force is not a prior cause to an object's effect, its acceleration. This suggest that there is simultaneous causality (given that Newton's laws are interpreted causally, that is, if one can in the first place find a relation of cause and effect in them). Hume discards simultaneous causation with a reduction argument. "If every effect," Todd Ryan notes, "occurs simultaneously with its cause, then we arrive at the absurd conclusion that there can be no causal (or indeed temporal) succession in the world." 28

Even in the Enquiries causation is constant conjunction; one thing or event is followed by another. This is inconsistent with a causal interpretation of Newton's laws of motion and the law of universal gravitation. In the relevant section of the Treatise, Hume ends up with a paradigmatically mechanistic statement of causation in dynamic laws. Importantly, he claims that impulse is the causally efficacious factor in the motion of an object:

Having thus discover'd or suppos'd the two relations of contiguity and succession to be essential to causes and effects, I find I am stopt short, and can proceed no farther in considering any single instance of cause and effect. Motion in one body is regarded upon impulse as the cause of motion in other (T 1.3.2.9; SBN 76-7, italics of the last sentence added by the author).

Hume's claim that an impulse of one body to another body is the cause of motion is in tension with Newton's second law of motion. Newton argues that "a change of motion is proportional to the motive force impressed" (Principia, Axioms, or the Laws of Motion). Hume's application of the term "impulse" can only stand for mechanical contact action. This does not imply that impulse is the only cause of change in motion of bodies. In the first Enquiry (EHU 4.12; SBN 30), Hume mentions other causes like elasticity, cohesion, and 
gravitation. They cannot be reduced to impulse. Still, the "communication of motion by impulse" is a particularly clear example of causality for Hume. When bodies collide, and the motion of the first object is communicated to the second, he cannot find anything else except contiguity, succession, and impulse. ${ }^{29}$ But Newton's term “impressed force" also includes centripetal forces, for which gravity is an example (Principia, Definitions 4 and 5). In Newton contact action is not required, whereas Hume's assumption is that physical contact is requisite for bodies to change their motion. Hume's position is thus what one would expect from a mechanical philosopher: Forces resemble percussions rather than spatially distant impressions. ${ }^{30}$

\subsection{The separability of causes and effects}

In the first Enquiry, Hume claims explicitly that cause and effect are distinctly separable: "In a word, then, every effect is a distinct event from its cause" (EHU 4.11; SBN 30). This claim suggests that Hume is a mechanical philosopher in the sense that he diverges from the preceding Aristotelian tradition in natural philosophy.

In the Aristotelian framework, various parts of a causal process are not distinctly separable. An acorn is potentially a tree. In its essence, an acorn strives to grow to be a tree. The final cause of the process, the resultant tree, is included in the potential cause, the acorn. According to the mechanical philosophy, objects change their state by external causes acting upon them. This is, in the broadest sense, the content of Descartes' first law: If there is to be any change in an object, there needs to be an external cause for it. ${ }^{31}$ In this mechanistic model of causation "it would be a category mistake," Walter Ott argues, "to think that an event, or a mode of a body, could include its effect." 32 
Hume's argument for the distinctness of causes and effects follows from his separability principle. Briefly put, the principle maintains that separability implies distinctness. Hume writes: "Whatever objects are separable are also distinguishable, and that whatever objects are distinguishable are also different" (T 1.1.7.3; SBN 18). Cause and effect stand for particular objects or events. They are separate from each other because one can be conceived without conceiving the other. There is no contradiction in conceiving a cause and not conceiving an effect: We can "conceive any effect to follow from any cause," Hume asserts (Abstract 11; SBN 650, see also T 1.3.14.13; SBN 161-2, and EHU 4.9-11; SBN 29-30).

In Hume's account, the mind has a threshold in forming ideas: there needs to be a minimum sensible, to wit, a simple impression. For example, I now perceive a white office desk and a red coffee mug in front of me. My visual perceptions of these objects evince that they are distinct. Their different colors enable me to decide that there are two different finite objects with distinct spatial boundaries. This does not of course explain why the objects are separate. This only raises the question of why the impressions causing the ideas are separate. However, this reasoning illustrates the point of why effects are not included in causes. My visual perceptions do not inform me whether the objects stand in a causal relation or not. Causation is a relation external to perceptions of objects or events. It is not included in them in any way.

In the first Enquiry (4.6; SBN 29), we find a lengthy argument for refusing to include effects in their causes in physical causation. The example Hume uses below is very typical for a mechanical philosopher; motion produced in the collision of billiard balls: 
The mind can never possibly find the effect in the supposed cause, by the most accurate scrutiny and examination. For the effect is totally different from the cause, and consequently can never be discovered in it. Motion in the second Billiard-ball is a quite distinct event from motion in the first; nor is there any thing in the one to suggest the smallest hint of the other.

Because of Hume's separability principle, his position is mechanistic also in the sense that it is incompatible with the notion of interaction in dynamics. Consider the following scenario explained by Newton's third law of motion. I press the table with my hand; the table presses my hand with equal and opposite force. What is the cause, and what is the effect in this scenario? Is my pressing of the table the cause, or the pressing coming from the table? In Newtonian dynamics forces are generated through interactions. Although Newton's second law is the causal law and his third law is rather a law of co-existence, ${ }^{33}$ it is still difficult to separate the supposed cause and the supposed effect in dynamic interactions (for forces appear between mass points). But this is what Hume's separability principle requires.

So far, I have shown that Hume assumes a causal and mechanistic stance on LoD. In the next section, I proceed to analyze the extent to which it is mechanistic. I shall argue that despite of Hume's mechanistic model of causation, he is not a full-blown mechanical philosopher. This is because he remains agnostic concerning the microstructure of matter. Most notably, he does not subscribe to the corpuscularian hypothesis in natural philosophy.

\section{The extent of Hume's mechanical philosophy}


To reiterate a criterion identified by Roux and Garber, mechanical philosophy adopts "an ontology according to which all natural phenomena can be understood in terms of the matter and motion of the small corpuscles that make up the gross bodies of everyday experience alone." This criterion is also apparent in Ephraim Chambers' definition of mechanical philosophy from the year 1728. It effectively equates mechanical philosophy with the corpuscular philosophy. Thus Chambers defines the term:

Mechanical Philosophy, is the same with the Corpuscular Philosophy; viz. that which explains the Effects of Nature, and the Operations of Corporeal Things, on the Principles of Mechanics; the Figure, Arrangement, Disposition, Motion, Greatness or Smallness of the Parts which compose natural Bodies. See Corpuscular. ${ }^{34}$

Boyle and Locke subscribe to this aspect of mechanical philosophy, but not Hume. Explaining the difference between these scholars clarifies the extent of Hume's mechanical philosophy.

In his "Grounds for and Excellence of the Corpuscular or Mechanical Philosophy," Boyle argues that the size, shape and motion of corpuscles, which make the "texture" (microstructure) of matter, determine all macroscopic corporeal phenomena. This "texture," for Boyle, is the structure that is "made out of minute and insensible corpuscles" of bodies. ${ }^{35}$

Locke is very sympathetic to Boyle on this issue. In explaining the texture of bodies, and how it relates to experiential macroscopic causation among bodies, both Boyle (Origin of Forms and Qualities, section 2) and Locke (Essay IV.iii.25) compare it to human-made machinery. Allison Kuklok elucidates Locke's explanatory strategy as follows: 
...the behavior of any macroscopic body is in part a function of its internal constitution, for example the more or less firm cohesion of its microscopic parts. We can thus see how our ignorance of the inner constitutions of macroscopic bodies makes the seemingly simple example of macroscopic causation, the impact and motion transfer between two billiard balls, opaque to us. The causal upshot is in part a function of the unknown real constitution of the material out of which the billiard balls are made. [...] But as Locke's remarks also make clear, we can provide explanations for such observable behavior. Such explanations take the form of hypotheses about the nature of a body's hidden internal constitution. [...] Reasoning based on this kind of modeling is just the kind of reasoning we can appeal in explaining, say, a locksmith's prediction that only one of several keys will turn a lock. ${ }^{36}$

The above explanation is based on an argument from analogy. A locksmith can predict which one of the several keys can open a lock. In the same way, an observer can predict the outcome of the collisions of macroscopic bodies. Neither the locksmith nor the observer relying on their senses have direct empirical access to the machinery of locks or bodies. Nevertheless, in both cases the observable effects ensue from the hidden internal microconstitutions of the lock and of the bodies. For Locke, the functioning of artifactual machinery is therefore analogous to causal efficaciousness in macroscopic causal relations. Kuklok maintains that Hume adopts Locke's view of mechanism's concept.

Kuklok might be perfectly right about Locke's position. However, I do not think that this interpretation is correct with regard to Hume. In my interpretation, in Hume causal reasoning is founded on experience of constant conjunctions of objects or events. The information we 
acquire of these objects or events is provided by perceptions according to the copy principle. According to this principle, simple ideas in the mind resemble simple impressions, and simple ideas are caused by their corresponding simple impressions (T 1.1.1.1; SBN 1-2). There is no evidence coming from our five senses to confirm the existence of corpuscles. Hume must remain agnostic on whether bodies are made of corpuscles, and whether this putative micro-constitution of matter determines macroscopic causation.

However, my interpretation does not contend that on Hume's account we could not have the idea of a corpuscle (or that the copy principle makes the term "corpuscle" a meaningless one). Considering the traditional, Democritean atomist doctrine,${ }^{37}$ a corpuscle is a body that has a certain shape, size, position and orientation. These are manifest features, all of which satisfy the copy principle. The features described by classic atomist doctrine or modern corpuscularianism are observable in the macroscopic bodies around us. In principle, a corpuscle is not imperceptible, and therefore it is not unconceivable. Hume states that it "is certain, that we can form ideas, which shall be no greater than the smallest atom of the animal spirits of an insect a thousand times less than a mite" (T 1.2.1.5; SBN 28). In Hume's time there were no microscopes of adequate resolution to detect the hypothetical corpuscles. So he does not find reasons to believe in the existence of corpuscles. This is a reservation that stems from inadequate technology; the copy principle does not rule out corpuscles.

Hume diverges from Boyle and Locke because in his rigidly empiricist and skeptical theory of perception and causation, we are not licensed to infer what the hidden micro-constitution of bodies is, or in what relation this putative constitution is to macroscopic bodily causation. This doubt concerning the texture of bodies arises, to quote from Graciela De Pierris, from Hume's “consistent and radical interpretation of the sensible phenomenological model of 
ultimate evidence." 38 In addition to De Pierris' formulation, Hume's doubt can be characterized as follows. For Hume, laws of nature are generalizations over regularities. He does not find anything that would ground these regularities, because there is no sensible evidence for that putative ground. ${ }^{39}$

One critical question should be raised here. Boyle and Locke posit corpuscles to explain observable phenomena. This basic point can be framed by using a vocabulary borrowed from our contemporary philosophy of science: we should believe in the existence of corpuscles because they are an inference to the best explanation (of explaining macroscopic bodily causation). Does Hume's account of causation rule out such an inference? I think the answer is yes. An inference to the best explanation does not guarantee an inference to the right explanation.

Hume does not apply abductive inference like Boyle and Locke in their argument from analogy. This is because his account of causation recognizes that in principle any thing may be the cause of another thing (T 1.3.14.13; SBN 161-2, Abstract 11; SBN 650, and EHU 4.911; SBN 29-30). The only way for us to have information of any causal relation is by experience. Hume defines experience as a memory and observation of species of objects being constantly conjoined (T 1.3.6.2; SBN 87). I remember having observed that every time I place my finger to a candle flame, I feel heat, and every time I put my hand into a bucket of ice I feel cold. Objects or events that stand for causes and effects need to be perceivable. So we know about these causal relations by experience. But we do not have the same experience when it comes to mechanist explanation of bodily causation. We do not perceive (even with the best microscopes available) the sizes, shapes, positions, or orientations of the corpuscles, and the way they relate to the collisions of average-size objects. We can only speculate this. 
A speculation like this is, in Hume's parlance, a causal hypothesis which goes beyond experience and should be declined ( $\mathrm{T}$ Intro 8; SBN xvii). Therefore Hume remains an agnostic on the existence of corpuscles, and their putative causal efficaciousness.

My interpretation is able to explain Hume's announced dismissal of Boyle's corpuscularian theory. In his History (VI, 540) ${ }^{40}$ Hume highly appreciates Boyle's experimental work with the air pump. Still he goes on to denote the corpuscularian position of Boyle's mechanical philosophy "imaginary":

Boyle improved the pneumatic engine invented by Otto Guericke, and was thereby enabled to make several new and curious experiments on the air as well as on other bodies: His chemistry is much admired by those who are acquainted with that art: His hydrostatics contain a greater mixture of reasoning and invention with experiment than any other of his works; but his reasoning is still remote from that boldness and temerity, which had led astray so many philosophers. Boyle was a great partizan of the mechanical philosophy; a theory, which, by discovering some of the secrets of nature, and allowing us to imagine the rest, is so agreeable to the natural vanity and curiosity of men.

The nuance of the preceding quote is mostly positive. Hume revers Boyle's experimentalism, and even partly his mechanical philosophy by contending that mechanical philosophy can discover "some of the secrets of nature." This is consistent with the fact that Hume is both a supporter of the British experimental tradition in natural philosophy and, in a relevant sense, a mechanical philosopher. His disagreement with Boyle shows the limits of his mechanical philosophy: Hume does not believe in Boyle's minute posits, the corpuscles. There is further 
textual evidence for this interpretation. In the next paragraph of History (VI, 542), Hume writes:

While Newton seemed to draw off the veil from some of the mysteries of nature, he shewed at the same time the imperfections of the mechanical philosophy; and thereby restored her ultimate secrets to that obscurity, in which they ever did and ever will remain.

Eric Schliesser reads the above quote as indicating "Hume's treatment of Boyle reveals that he thought it was a good thing Newton falsified the mechanical philosophy." But, he adds: "Hume acknowledges that the mechanical philosophy could offer some successful explanations." 41 Schliesser's reading is consistent with my position: Hume discredits corpuscularianism and simultaneously thinks that mechanical philosophy can in part provide cogent explanations of natural phenomena.

\section{Conclusion: The tacit assumption of mechanism}

Regarding Hume's position on LoD and mechanism, this article has provided two viewpoints. The first viewpoint is positive: Hume does indeed model his causal philosophy with the aid of mechanism. This is apparent in the criteria and the arguments of contiguity and separability of causes and effects. The second viewpoint is negative: Hume is not a fullblown mechanical philosopher. He is agnostic on whether the hidden microstructure of bodies is machinelike, as the corpuscularian natural philosophy maintains. The two viewpoints are compatible if we accept the main thesis of this article: Hume's position on LoD tacitly assumes a mechanism. 
When this conclusion is accepted, we can also see that Hume's position is in crucial tension with the key results of Newtonian dynamics. Although Hume is (and rightly so, although I cannot defend this claim here) traditionally been viewed as a Newtonian philosopher, his concept of causation is inconsistent with a causal interpretation of Newton's laws of motion and his law of universal gravitation. As Andrew Janiak has it, "the mechanists," whom, in this case, can be seen to include Hume,

failed to recognize that they retained a residue of the ordinary image [as opposed to the "scientific image," to paraphrase Sellars' famous figure ${ }^{42}$ ] of the world in their conception of causation. After all, why should we think that all natural change occurs through contact action? The reason that it sounds outlandish to say (e.g.) that the Sun impresses a force on Jupiter is that this deviates from our ordinary experience of causal interactions; nothing in ordinary experience suggests that the Sun could move Jupiter. Thus Newton transcends the mechanist project by jettisoning the last bastion of ordinary beliefs about causation. ${ }^{43}$

Hume still holds on to some pervasive assumptions of the push-and-shove mechanistic model of the universe. In this model, motion of bodies is generated via percussions. To fully accept the results of Newtonian dynamics - from a perspective of a causal interpretation of laws, at least ${ }^{44}$ - one should abandon such a mechanistic model, and replace it with some other concept of causation. 


\section{NOTES}

First, I must thank the referees of Hume Studies. Especially the first referee did an amazing job. I have presented this paper at the $16^{\text {th }}$ Bucharest-Princeton Seminar in Early Modern Philosophy, on July 16, 2016 in Alba-Iulia, and at the $9^{\text {th }}$ Nordic Workshop in Early Modern Philosophy, on May 27, 2016 at the University of Tampere. Many thanks to the constructive criticism and feedback I received from the audiences of both seminars.

${ }^{1}$ Timothy McGrew, "Miracles," ['Miracles'] The Stanford Encyclopedia of Philosophy (Winter 2015 Edition), Edward N. Zalta (ed.), URL = http://plato.stanford.edu/archives/win2015/entries/miracles/, section 3.3, details the impact of Hume's discussion of miracles on subsequent history of philosophy and contemporary philosophy, including a lengthy list of references.

${ }^{2}$ Markus Schrenk, "Humeanism and Nonhumeanism about Laws" ['Laws'], PhilPapers category of General Philosophy of Science, available at: http://philpapers.org/browse/humeanism-and-nonhumeanism-about-laws, introduces the main tenets of the two positions and lists their main proponents.

3 By focusing on dynamic laws, this article does not concern Hume's possible references to the laws of optics. For this reason, I do not speak of Hume's conception of laws of physics in general but of his conception of the laws of dynamics in particular.

4 References to all of Hume's works are in accordance with Hume Society's recommendations. The internet portal davidhume.org and the Selby-Bigge/Nidditch abbreviations and numberings are used when referring to the following works: A Treatise of Human Nature: Being an Attempt to Introduce the Experimental Method of Reasoning into Moral Subjects [Treatise], (London: John Noon, 1739), 'An Abstract of a Book Lately 
Published, Entituled A Treatise of Human Nature' ['Abstract'], (London: C. Borbet, 1740), Philosophical Essays concerning Human Understanding [the first Enquiry] [London: A. Millar, 1748], An Enquiry concerning the Principles of Morals [the second Enquiry], (London: A. Millar, 1751).

${ }^{5}$ This depiction is based on the "Brief Contents" section of Randall D. Knight, Physics for Scientists and Engineers [Physics] (San Francisco: Pearson Addison-Wesley, 2008).

${ }^{6}$ Michael Barfoot, "Hume and the Culture of Science in the Early Eighteenth Century" ['Hume and Culture'] in Michael Alexander Stewart (ed.) Studies in the Philosophy of the Scottish Enlightenment (Oxford: Oxford University Press, 1990), provides evidence that Hume participated in a class taught by Robert Steuart in 1724-5. Norman Kemp Smith, The Philosophy of David Hume: A Critical Study of its Origins and Central Doctrines [Philosophy of Hume] (London: Macmillan, 1941) observes that Steuart "is reported to have been in his earlier years a Cartesian, and later a Newtonian." If this observation were correct, it would be consistent with my interpretation which asserts that Hume's natural philosophy reflects both Cartesian and Newtonian elements. For the discussion of Hume's education and knowledge of natural philosophy, see also Margaret Schabas, The Natural Origins of Economics [Origins of Economics] (London: The University of Chicago Press, 2005), 65-70, and Graciela De Pierris, Ideas, Evidence \& Method. Hume's Skepticism \& Naturalism concerning Knowledge \& Causation [Hume's Skepticism \& Naturalism] (Oxford: Oxford University Press, 2015), section 3.5.

${ }^{7}$ Hume speaks of a kind of mental attraction in the Treatise (T 2.1.4.3; SBN 283). This metaphor has been understood as an expression of Hume's debt to Newtonian natural philosophy. It might be that Hume implemented parts of natural philosophy in his science of human nature. But he is also arguing that the aim of his science of humanity is different from that of natural philosophy. He does not "explain natural and physical causes" of our 
perceptions because "the examination of them wou'd lead me too far from my present subject, into the sciences of anatomy and natural philosophy" (T 2.1.1.2; SBN 275-6). In the first Book of the Treatise, he is first and foremost interested in issues such as perception, memory, personal identity, and imagination. This indicates that Hume's science of human nature is more like cognitive psychology (or its proto-form) than some part of natural philosophy (like physics).

${ }^{8}$ René Descartes, Principles of Philosophy ['Pr'], V. R. Miller and R. P. Miller (trans.) (Dordrecht: Kluwer Academic, 1983) and Isaac Newton, The Principia: Mathematical Principles of Natural Philosophy [Principia], I. Bernard Cohen, Anne Whitman and Julia Budentz (trans.), (Los Angeles: California University Press, 1999).

9 Edward Slowik, "Descartes' Physics," ['Descartes' Physics'] The Stanford Encyclopedia of Philosophy (Summer 2014 Edition), Edward N. Zalta (ed.), URL = http://plato.stanford.edu/archives/sum2014/entries/descartes-physics/, at section 4, notes that in formulating his first law, Newton also needed to consider Descartes' second law of nature, according to which "all movement is, of itself, along straight lines" (Pr II 39).

${ }^{10}$ Steven Nadler, "Malebranche on Causation," in Steven Nadler (ed.) The Cambridge Companion to Malebranche (Cambridge: Cambridge University Press, 2000, 112-38), at 1156.

${ }^{11}$ Under the ideal condition where the balls have identical masses and the collision is perfectly elastic. In Hume's reference to law II, he might be using the word "motion" as synonymous with "momentum." If this were so, the idealizing conditions, according to which colliding bodies have equal masses, are unnecessary, since mass is already used to define momentum.

12 The problem Hume tackles in EHU 4.13 is whether factual propositions expressed in mathematical terms, such as the proposition concerning the law of conservation of 
momentum, are themselves a priori necessities, like the propositions of pure mathematics. Matias Slavov, "Hume's Fork and Mixed Mathematics" ['Fork and Mathematics'], Archiv für Geschichte der Philosophie, 99 (2017), 102-119, argues that the propositions of mixed mathematics are factual because they assume the uniformity principle, unlike the propositions of pure mathematics.

${ }^{13}$ Charles Twardy, Causation, Causal Perception, and Conservation Laws [Laws], Master's Thesis in History and Philosophy of Science at Indiana University, at 29, and Alan Gabbey, 'Huygens and mechanics' ['Huygens'], in H. J. M. Bos et al. (ed.), Studies on Christian Huygens (Lisse: Swets \& Zeitlinger B.V., 1980), 166-99, at 177. We would probably expect Hume to have said that "a small mass" or "a small weight" rather than "a small force" is proportional to the weight raised. However, equating forces with lifting weights seems very typical for the Cartesian tradition of natural philosophy of Hume's time. Ephraim Chambers', Cyclopaedia, or an Universal Dictionary of Arts and Sciences [Cyclopaedia] (London: James and John Knapton, 1728), at 521, dictionary has also a very similar formulation of the general conservation law (as expressed in Hume's rendition of definition in law III): "Wherefore in any Machine or Engine, if the Velocity of the Power be made to the Velocity of the Weight: reciprocally as the Weight is to the Power; then shall the Power always sustain, or is the Power be a little increas'd, move the Weight."

${ }^{14}$ Max Jammer, Concepts of Force: A Study in the Foundations of Dynamics [Concepts of Force] (Cambridge, Massachusetts: Harvard University Press, 1957), at 127.

15 This issue is closely related to the debate whether Newton had the notion of force field. Howard Stein, "On the Notion of Field in Newton, Maxwell, and Beyond" ['Notion of Field'], in Roger H. Stuewer et al. (ed.), Historical Perspectives of Science (Minneapolis: University of Minnesota Press, 1970), 264-87, is a classical article defending the view that Newton did use the concept of gravity field. Eric Schliesser, "Without God: Gravity as a 
Relational Quality of Matter in Newton's Treatise" ['Relational Quality'], in Dana Jalobeanu and Peter R. Anstey (eds.), Vanishing Matter and the Laws of Motion. Descartes and Beyond (New York: Routledge, 2011), 80-102, at 93-4, challenges Stein's reading.

${ }^{16}$ In Definition 10 of his "De Gravitatione," Newton claims that "gravity is the force in a body impelling it to descend." This suggest that there has been a change in Newton's thought: before the Principia, he saw force to be something in a body, whereas in the Principia force is an interactive relation among masses. Isaac Newton, "De Gravitatione," in Isaac Newton and Andrew Janiak (ed.), Newton: Philosophical Writings [Newton: Writings] (Cambridge: Cambridge University Press, 2004), 12-39. In rule 3 of the Rules for the Study of Natural Philosophy in the Principia, Newton explicitly says that gravity is not essential to bodies.

${ }^{17}$ See also Hume's doctrine of relations in the Treatise 1.3.1, which is an important background for understanding the distinction Hume draws in the fourth section of the first Enquiry.

18 This brings up the problem that how can Hume explain matters of fact that are not causal. For example, propositions like "Cats and dogs exist," "This pint of beer is cold," and "All humans are mortal" are not causal propositions, but still indeed factual. I do not know how Hume can explain this.

${ }^{19}$ Sophie Roux and Daniel Garber, "Introduction" in The Mechanization of Natural Philosophy [Mechanization] (Boston Studies in the Philosophy of Science 282, Dordrecht, Heidelberg, New York, London: Springer, 2013), xi-xviii, at xi.

${ }^{20}$ Newton, “Correspondence with Richard Bentley [1692-3]," Newton: Writings, at 103.

${ }^{21}$ Here I am excluding God's omnipresence that Newton articulates in the General Scholium, Principia, at 940-1, as I feel this point is not relevant to the present article. 
${ }^{22}$ Mary B. Hesse, Forces and Fields: A Study of Action at a Distance in the History of Physics [Forces and Fields] (London and New York: T. Nelson, 1962), Chapter 7.

${ }^{23}$ Gottfried Leibniz and Samuel Clarke, A Collection of Papers, Which passed between the late Learned Mr. Leibniz, and Dr. Clarke, In the Years 1715 and 1716 [Leibniz-Clarke Correspondence] (London: James Knapton, 1717), at 273.

${ }^{24}$ It is likely that Malebranche's discussion on causation in his Search after Truth [Search], Thomas M. Lennon and Paul J. Olscamp (eds., trans.) (Cambridge: Cambridge University Press, 1977), influenced Hume. In Lisa Downing's interpretation, “Occasionalism and Strict Mechanism: Malebranche, Berkeley, Fontenelle” ['Occasionalism and Mechanism'] in Christia Mercer and Eileen O’Neill (eds.) Early Modern Philosophy: Mind, Matter, and Metaphysics (New York: Oxford University Press, 2005), Malebranche adheres to strict mechanical philosophy which allows bodies to interact solely by means of contact by impact.

${ }^{25}$ In this issue, Descartes' and Hume's argumentative paths are certainly very different. Descartes' argument is a corollary of his metaphysics of substance. There are two substances in the world: minds and bodies. The attribute of a mind is thought, whereas the attribute of a body is extension. Hume's argumentation is based on his copy principle. The mind has a threshold in forming adequate representing ideas. There are minimum sensible items, extended finite tactual or visual points, which are the source for the (abstract) idea of space. Although the two authors have markedly different ways in which they reach at their conclusions, they nevertheless both conclude that space is extension.

26 Whether Hume completely rejects action at a distance is not obvious. In Treatise (1.2.5.26n) he remarks that it is not clear "whether or not the invisible and intangible distance be always full of body." He does not find a "very decisive arguments on either side" (For a thorough reading on fictitious distance, see Miren Boehm, "Filling the Gaps in Hume's 
Vacuums" ['Hume's Vacuums'] Hume Studies 38 (2012), 79-99). There can be causally related existent objects even though the objects are not spatial beings, as Hume's metaphysical maxim in T 1.4.5.10 states. However, when it comes to bodies, Hume's talk of an object being "ever so little remov'd" (T 1.3.2.6; SBN 75) seems to in fact indicate that for bodies to be causally related there must be contact among them. Two bodies cannot be considered as causes and effects if they do not touch each other. Hume is explicit on this matter in the "Abstract" 9 of the Treatise, where he says that "contiguity in time and place is therefore a requisite circumstance to the operation of all causes." He highlights the need of physical contact, that is, touch, when he addresses the causal relation among two billiard balls: "The first ball is in motion; touches the second; immediately the second is in motion: and when I try the experiment with the same or like balls, in the same or like circumstances, I find, that upon the motion and touch of the one ball, motion always follows in the other" (Abstract 9; SBN 650, italics added by the author). Causation regarding bodies is of course different from events, which only need to be in "next-to" relation to each other.

27 Katherine Dunlop, "What Geometry Postulates: Newton and Barrow on the relationship of mathematics to nature" ['Newton and Barrow'] in Andrew Janiak and Eric Schliesser (eds.) Interpreting Newton: Critical Essays [Interpreting Newton], (New York: Cambridge University Press, 2012), 69-101, at 86.

28 Todd Ryan, "Hume's Argument for the Temporal Priority of Causes" ['Temporal Priority'] Hume Studies, 29 (2003), 29-41, at 30.

${ }^{29}$ See David Fate Norton's and Mary J. Norton's, David Hume, A Treatise of Human Nature, Volume 2: Editorial Material ['Editorial Material'] (New York: Clarendon Press), at 734, explanatory note on $\mathrm{T}$ 1.3.2.9, where they analyze the meaning of the term impulse and its historical background. 
${ }^{30}$ Percussion is also one form of impressed force in Newton's listing of the three types of dynamic forces (Principia, Definition 4). However, mechanical forces such as percussion are included in dynamical forces, but not the other way around; centripetal force is excluded by the mechanical philosophy.

31 Katherine Brading, “Newton's law-constitutive approach to bodies: a response to Descartes” ['Newton's approach'], Interpreting Newton, at 13, fn. 1.

${ }^{32}$ Walter Ott, Causation and Laws of Nature in Early Modern Philosophy [Causation and Laws] (Oxford: Oxford University Press, 2009), at 14.

${ }^{33}$ Michael Tooley, "Probability and Causation," in Phil Dowe and Paul Noordhof (eds.) Cause and Chance: Causation in an Indeterministic World ['Cause and Change'] (New York: Routledge, 2004), 77-119, at 88.

${ }^{34}$ Chambers, Cyclopaedia, at 521.

35 Robert Boyle, "The Excellency and Grounds of the Corpuscular or Mechanical Philosophy" ['Excellency and Grounds'], in Michael R. Matthews (ed.) The Scientific Background to Modern Philosophy: Selected Readings, [Background to Modern Philosophy], (Indianapolis/Cambridge: Hackett Publishing Company, 1989), 111-23, at 117.

${ }^{36}$ Allison Kuklok, "The Status of Mechanism in Hume's Account of Causal Power" ['Status of Mechanism'], Proceedings of the $42^{\text {nd }}$ International Hume Society Conference Stockholm 2015, 304-20, at 317.

37 Sylvia Berryman, "Democritus," The Stanford Encyclopedia of Philosophy (Winter 2016 Edition), $\quad$ Edward N. Zalta (ed.), URL <https://plato.stanford.edu/archives/win2016/entries/democritus/>.

${ }^{38}$ De Pierris, Hume's Skepticism \& Naturalism, at 14. Note that De Pierris' rendition allows that corpuscles are in principle observable. In footnote 25 she writes: "Causation 
enables us to make inferences from instances of constant conjunction that have been observed to those that have not yet been observed but still are, in principle, observable."

39 This is also one way in which Hume diverges from Boyle and Locke. All three philosophers (roughly) assume what Ott, Causation and Laws, in chapter 1.1., calls the 'bottom-up' analysis of laws. In this view, laws of nature are nothing more than convenient ways to state relations among the properties (quantities like mass, velocity and distance) of bodies. Laws do not float free of bodies, like in the alternative 'top-down' analysis of laws. For Boyle, Locke and Hume laws of nature are generalizations over regularities. But what grounds these regularities? Boyle and Locke think that mechanism (or causal power) is that ground. But Hume, given the limited empirical evidence of the micro-structure bodies in his time, thinks we are not justified in asserting that natural regularities are grounded in anything at all.

${ }^{40}$ David Hume, The History of England, from the Invasion of Julius Caesar to the Revolution in 1688, in Six Volumes [History], (Indianapolis: Liberty Fund, 1983).

${ }^{41}$ Eric Schliesser, "Hume's Newtonianism and Anti-Newtonianism,” ['Newtonianism'] The Stanford Encyclopedia of Philosophy (Winter 2008 Edition), Edward N. Zalta (ed.), URL $=<$ http://plato.stanford.edu/archives/win2008/entries/hume-newton/ $>$.

${ }^{42}$ Wilfrid Sellars, "Philosophy and the Scientific Image of Man,” ['Scientific Image'] in Robert Colodny (ed.), Frontiers of Science and Philosophy (Pittsburgh: University of Pittsburgh Press, 1962), 35-78.

43 Andrew Janiak, "Three concepts of causation in Newton," ['Concepts of causation'], Studies in History and Philosophy of Science Part A, 44 (2013), 393-407, at 397.

44 There certainly is an option to not to interpret laws in terms of causes and effects. This is not the option for Hume but it is possible to recognize a long acausal tradition in the philosophy of physics, including, by and large, Thomas Reid, Essays on the Active Powers of 
Man ['Active Powers'], Knud Haakonssen and James Harris (eds.) (Edinburgh: Edinburgh University Press, 2010), Auguste Comte, Cours de philospohie positive, leçons 46-51 ['Philosophie positive'], (Paris: Hermann, 2012), Ernst Mach, The Science of Mechanics ['Mechanics'], Thomas McCormack (trans.) (Chicago, London: Open Court, 1919), Friedrich Waismann, Causality and Logical Positivism ['Causality and Positivism'], B. F. McGuinness (ed.) (Dordrecht: Springer, 2011), John D. Norton, 'Causation as Folk Science' ['Folk Science'], Philosopher's Imprint, 3 (2003), 1-22, and James Ladyman and Don Ross, Every Thing Must Go: Metaphysics Naturalized ['Metaphysics Naturalized'], (New York: Oxford University Press, 2007).

\section{WORKS CITED:}

Barfoot, Michael. "Hume and the Culture of Science in the Early Eighteenth Century" in Michael Alexander Stewart (ed.) Studies in the Philosophy of the Scottish Enlightenment. Oxford: Oxford University Press, 1990.

Berryman, Sylvia. "Democritus," The Stanford Encyclopedia of Philosophy (Winter 2016 Edition), $\quad$ Edward $\quad$ Zalta (ed.), URL <https://plato.stanford.edu/archives/win2016/entries/democritus/>.

Brading, Katherine. "Newton's law-constitutive approach to bodies: a response to Descartes" in Andrew Janiak and Eric Schliesser (eds.) Interpreting Newton: Critical Essays (New York: Cambridge University Press, 2012), 13-32.

Boehm, Miren. "Filling the Gaps in Hume's Vacuums” Hume Studies 38 (2012), 79-99. 
Boyle, Robert. "The Excellency and Grounds of the Corpuscular or Mechanical Philosophy" in Michael R. Matthews (ed.) The Scientific Background to Modern Philosophy: Selected Readings (Indianapolis/Cambridge: Hackett Publishing Company, 1989), 111-23.

Chambers, Ephraim. Cyclopaedia, or an Universal Dictionary of Arts and Sciences. London: James and John Knapton, 1728.

Comte, Auguste. Cours de philospohie positive, leçons 46-51. Paris: Hermann, 2012.

De Pierris, Graciela. Ideas, Evidence \& Method. Hume's Skepticism \& Naturalism concerning Knowledge \& Causation. Oxford: Oxford University Press, 2015.

Descartes, René. Principles of Philosophy, V. R. Miller and R. P. Miller (trans.). Dordrecht: Kluwer Academic, 1983.

Downing, Lisa. "Occasionalism and Strict Mechanism: Malebranche, Berkeley, Fontenelle” in Christia Mercer and Eileen O’Neill (eds.) Early Modern Philosophy: Mind, Matter, and Metaphysics (New York: Oxford University Press, 2005).

Dunlop, Katherine. "What Geometry Postulates: Newton and Barrow on the relationship of mathematics to nature" in Andrew Janiak and Eric Schliesser (eds.) Interpreting Newton: Critical Essays (New York: Cambridge University Press, 2012), 69-101. 
Gabbey, Allan. "Huygens and mechanics," in H. J. M. Bos et al. (ed.), Studies on Christian Huygens (Lisse: Swets \& Zeitlinger B.V., 1980), 166-99.

Hesse, Mary B. Forces and Fields: A Study of Action at a Distance in the History of Physics. London and New York: T. Nelson, 1962.

Hume, David. The History of England. Edited by William B. Todd, 6 vols. Indianapolis: Liberty Classics, 1983.

Hume, David. Dialogues Concerning Natural Religion. Edited by Dorothy Coleman. Cambridge: Cambridge University Press, 2007.

Hume, David. Enquiries Concerning the Principles of Human Understanding and Concerning the Principles of Morals. Edited by L. A. Selby-Bigge, revised by P. H. Nidditch, 3rd ed. Oxford: Clarendon Press, 1975.

Hume, David. Enquiries Concerning Human Understanding and Concerning the Principles of Morals. Edited by L. A. Selby-Bigge. Oxford: Oxford University Press, 1975.

Hume, David. An Enquiry concerning Human Understanding. Edited by Tom L. Beauchamp. New York: Oxford University Press, 2006.

Hume, David. A Treatise of Human Nature. Edited by David Fate Norton and Mary J. Norton. New York: Oxford University Press, 2000. 
Hume, David. An Enquiry concerning the Principles of Morals. Edited by Tom. L. Beauchamp. Oxford: Oxford University Press, 1998.

Hume, David. A Treatise of Human Nature. Edited by L. A. Selby-Bigge. New York: Oxford University Press, 1974.

Jammer, Max. Concepts of Force: A Study in the Foundations of Dynamics. Cambridge, Massachusetts: Harvard University Press, 1957.

Janiak, Andrew. "Three concepts of causation in Newton," Studies in History and Philosophy of Science Part A, 44 (2013), 393-407.

Kemp Smith, Norman. The Philosophy of David Hume: A Critical Study of its Origins and Central Doctrines. London: Macmillan, 1941.

Knight, Randall D. Physics for Scientists and Engineers. San Francisco: Pearson AddisonWesley, 2008.

Kuklok, Allison. "The Status of Mechanism in Hume's Account of Causal Power" Proceedings of the $42^{\text {nd }}$ International Hume Society Conference Stockholm 2015, 304-20.

Ladyman, James and Don Ross, Every Thing Must Go: Metaphysics Naturalized. New York: Oxford University Press, 2007. 
Leibniz, Gottfried and Samuel Clarke, A Collection of Papers, Which passed between the late Learned Mr. Leibniz, and Dr. Clarke, In the Years 1715 and 1716. London: James Knapton, 1717.

Mach, Ernst. The Science of Mechanics, Thomas McCormack (trans.). Chicago, London: Open Court, 1919.

Malebranche, Nicolas. Search after Truth, Thomas M. Lennon and Paul J. Olscamp (eds., trans.). Cambridge: Cambridge University Press, 1977.

McGrew, Timothy. "Miracles," The Stanford Encyclopedia of Philosophy (Winter 2015 Edition), $\quad$ Edward $\quad$ Zalta (ed.), URL http://plato.stanford.edu/archives/win2015/entries/miracles/.

Nadler, Steven. "Malebranche on Causation," in Steven Nadler (ed.) The Cambridge Companion to Malebranche. Cambridge: Cambridge University Press, 2000, 112-38.

Newton, Isaac. "De Gravitatione," in Isaac Newton and Andrew Janiak (ed.), Newton: Philosophical Writings (Cambridge: Cambridge University Press, 2004), 12-39.

Newton, "Correspondence with Richard Bentley [1692-3]," Newton: Writings, in Isaac Newton and Andrew Janiak (ed.), Newton: Philosophical Writings (Cambridge: Cambridge University Press, 2004). 
Newton, Isaac. The Principia: Mathematical Principles of Natural Philosophy, I. Bernard Cohen, Anne Whitman and Julia Budentz (trans.). Los Angeles: California University Press, 1999.

Norton, David Fate, and Mary J. Norton's, David Hume, A Treatise of Human Nature, Volume 2: Editorial Material. New York: Clarendon Press, 2007.

Norton, John D. 'Causation as Folk Science', Philosopher's Imprint, 3 (2003).

Ott, Walter. Causation and Laws of Nature in Early Modern Philosophy. Oxford: Oxford University Press, 2009.

Reid, Thomas. Essays on the Active Powers of Man, Knud Haakonssen and James Harris (eds.). Edinburgh: Edinburgh University Press, 2010.

Roux, Sophie and Garber, Daniel. "Introduction" in The Mechanization of Natural Philosophy (Boston Studies in the Philosophy of Science 282, Dordrecht, Heidelberg, New York, London: Springer, 2013), xi-xviii.

Ryan, Todd. "Hume's Argument for the Temporal Priority of Causes." Hume Studies, 29 (2003), 29-41.

Schabas, Margaret. The Natural Origins of Economics. London: The University of Chicago Press, 2005. 
Schliesser, Eric. "Without God: Gravity as a Relational Quality of Matter in Newton's Treatise", in Dana Jalobeanu and Peter R. Anstey (eds.), Vanishing Matter and the Laws of Motion. Descartes and Beyond (New York: Routledge, 2011), 80-102.

Schliesser, Eric. "Hume's Newtonianism and Anti-Newtonianism," The Stanford Encyclopedia of Philosophy (Winter 2008 Edition), Edward N. Zalta(ed.), URL = <http://plato.stanford.edu/archives/win2008/entries/hume-newton/>.

Schrenk, Markus. "Humeanism and Nonhumeanism about Laws," PhilPapers category of General Philosophy of Science, available on: http://philpapers.org/browse/humeanism-andnonhumeanism-about-laws.

Sellars, Wilfrid. "Philosophy and the Scientific Image of Man," in Robert Colodny (ed.), Frontiers of Science and Philosophy (Pittsburgh: University of Pittsburgh Press, 1962), 3578.

Slavov, Matias. "Hume's Fork and Mixed Mathematics", Archiv für Geschichte der Philosophie 99 (2017), 102-119.

Slowik, Edward. "Descartes' Physics," The Stanford Encyclopedia of Philosophy (Summer 2014 Edition), $\quad$ Edward $\quad$ Zalta (ed.), URL = http://plato.stanford.edu/archives/sum2014/entries/descartes-physics/. 
Stein, Howard. "On the Notion of Field in Newton, Maxwell, and Beyond", in Roger H. Stuewer et al. (ed.), Historical Perspectives of Science (Minneapolis: University of Minnesota Press, 1970).

Tooley, Michael. "Probability and Causation," in Phil Dowe and Paul Noordhof (eds.) Cause and Chance: Causation in an Indeterministic World (New York: Routledge, 2004), 77-119.

Twardy, Charles. Causation, Causal Perception, and Conservation Laws, Master's Thesis in History and Philosophy of Science at Indiana University.

Waismann, Friedrich. Causality and Logical Positivism, B. F. McGuinness (ed.). Dordrecht: Springer, 2011. 